\title{
ski can cause selective growth of skeletal muscle in transgenic mice
}

\author{
Pramod Sutrave, ${ }^{1}$ Alan M. Kelly, ${ }^{2}$ and Stephen H. Hughes ${ }^{1}$ \\ ${ }^{1}$ National Cancer Institute-Frederick Cancer Research and Development Center, ABL-Basic Research Program, Frederick, \\ Maryland 21701-1013 USA; 'University of Pennsylvania, School of Veterinary Medicine, Department of Pathology, \\ Philadelphia, Pennsylvania 19140 USA
}

\begin{abstract}
We have created several lines of mice that contain a truncated chicken c-ski cDNA linked to an MSV LTR promoter. Adult mice from three independent lines show large increases in skeletal muscle. All three lines of mice express high levels of c-ski mRNA and protein in skeletal muscle. All other tissues examined show little or no expression of the c-ski transgene. The muscles of one of the three lines were examined in more detail. Type II fast fibers undergo selective hypertrophy in affected muscles of this line.
\end{abstract}

[Key Words: ski; transgenic mice; muscle]

Received June 8, 1990; revised version accepted July 16, 1990.

Viruses that contain the v-ski oncogene are not only capable of causing morphological transformation in vitro but also can induce myogenic differentiation (Stavnezer et al. 1981, 1986; Li et al. 1986; Colmenares and Stavnezer 1989). Viruses that carry and express c-ski cDNAs also induce foci and myogenic differentiation (Sutrave et al. 1990; P. Sutrave and E. Stavnezer, unpubl.). This suggests the possibility that the ski oncogene is bifunctional, because the two known functions of ski, transformation and differentiation, would appear to be contradictory properties. Comparisons of the properties of two forms of c-ski that are related by alternative splicing and of several v-ski and c-ski deletion mutants have shown that the portions of ski required for transformation and differentiation are quite similar (P. Sutrave and S. Hughes, unpubl.; E. Stavnezer, pers. comm.). These results suggest that the ability of c-ski and $\mathrm{v}$-ski to cause transformation and induce differentiation may be related aspects of a single property of $s k i$ rather than two separate functions.

Relatively little is known about the biochemical functions of the Ski proteins. All of the biologically active forms of $\mathrm{c}$-ski and $\mathrm{v}$-ski that have been studied are localized primarily in the nucleus (Barkas et al. 1986; Sutrave et al. 1990). When the c-ski proteins are overexpressed in chicken cells, different forms of c-ski differ in their subnuclear localization; however, the significance of these differences, if any, is as yet unclear. When chromatin condenses for cell division, the overexpressed c-ski proteins are associated with the condensed chromatin $\mathrm{Su}$ trave et al. 1990). Biochemical studies have also shown that at least one form of c-ski can bind to DNA in the presence of other proteins (Nagase et al. 1990).

None of the available data make it possible to infer the normal function of c-ski in terms of its role in growth and development (if any) or to have any direct insight into its mode of action. In an attempt to gain some insight into c-ski function, we have produced a deleted version of a cloned chicken c-ski cDNA /which is active in both the in vitro transformation and myogenic differentiation assays) and introduced this truncated cloned cDNA into the germ line of mice under the control of a murine sarcoma virus long terminal repeat (MSV LTR). The MSV LTR is capable of causing the expression of linked sequences in a number of tissues in transgenic mice (Khillan et al. 1987; D. Cleveland, pers. comm.). We obtained three independent lines of mice, all of which express ski at high levels in skeletal muscle and have greatly increased skeletal muscle mass. A fourth line that carries the same transgene does not express the truncated c-ski at high levels and does not show the muscular phenotype.

\section{Results}

We have described the isolation of cDNAs that appear to derive from three alternatively spliced forms of chicken c-ski mRNA. The largest form, which has been called FB29, contains sequences that derive from all seven coding exons of c-ski and, judged by DNA sequence, encodes a c-ski protein of 750 amino acids. A derivative of the FB29 clone, which we have called $\triangle$ FB29, has a frameshift mutation in the fifth coding exon and is predicted to give rise to a protein of 448 amino acids, of which the first 436 are identical to the first 436 amino acids of the FB29 form of c-ski. The $\triangle F B 29$ cDNA has been introduced into a replication-competent avian retroviral vector (Hughes et al. 1987; Sutrave et al. 1990). This vector induces the synthesis of a $50-\mathrm{kD}$ c-ski protein in chicken embryo fibroblasts and can induce both 
transformation and myogenic differentiation in vitro (Sutrave et al. 1990; P. Sutrave and E. Stavnezer, unpubl.).

The $\triangle \mathrm{FB} 29$ cDNA was also introduced into the pMEX expression plasmid (for details, see Materials and methods). This places the truncated c-ski cDNA between an MSV LTR and an SV40 polyadenylation site (see Fig. 1). The plasmid was digested with PvuI and $\mathrm{NruI}$ to release the expression cassette. The expression cassette was purified by gel electrophoresis and introduced into fertilized mouse eggs by microinjection. Forty-four founder mice that carried the c-ski transgene were obtained after two independent injections. The mice were identified by dot blot analysis of DNA isolated from tail clips. This analysis was confirmed by Southern transfer. Three of the 44 founder mice showed a distinct muscle phenotype (TG 8566 , TG 8821 , and TG 8562). These three founders and a single mouse that contained unrearranged copy of the complete transgene but did not show any phenotype (TG 8542 ) were used to generate lines. Southern transfer analysis of DNA from TG 8566 , TG 8821 , TG 8562 , and TG 8542 suggests that the site of integration of the transgene in each line is different and the copy number varies from $\sim 5$ to 35 copies per genome (data not shown).

Mice from three of the transgenic lines (TG 8566, TG 8821, TG 8562) had a similar distinct appearance resulting from abnormal muscle growth. The majority of the skeletal muscles are involved. Mice with this phenotype can be readily identified by looking for enlarged limb and jaw muscles (Fig. 2).

Because the phenotype was obtained with three separate founders, the most reasonable explanation is that the phenotype was caused by the chicken c-ski transgene. We therefore examined all four lines of mice, three with the muscular phenotype and one that did not have an observable phenotype, for the expression of the transgene.

\section{Expression of transgene}

Expression of the truncated chicken c-ski cDNA in the transgenic animals was studied by analyzing total RNA

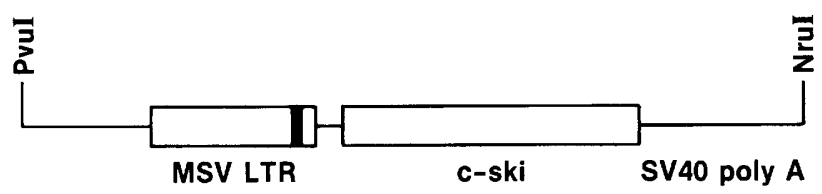

Figure 1. The c-ski expression cassette. A truncated chicken c-ski cDNA was introduced into the eukaryotic expression plasmid pMEX between the MSV LTR and the SV40 polyadenylation site. The details of the construction are given in Materials and methods. The PvuI-NruI segment was isolated by gel electrophoresis, following double digestion of the plasmid. The linear DNA was used to create the transgenic mice by microinjection of fertilized eggs. The box labeled MSV LTR reflects the tripartite nature of the LTR. The left side of the box represents U3; the solid vertical bar, $R$; and the open box at the right end of the LTR, U5. by Northern transfer. Total RNA from spleen, lung, brain, kidney, liver, stomach, heart, and leg (skeletal) muscle was isolated as described in Materials and methods. Twenty micrograms of total RNA was used; and the results are shown in Figure 3. All three lines with the phenotype (TG 8566, TG 8821, and TG 8562) expressed a $2.5-\mathrm{kb}$ chicken $\mathrm{c}$-ski-specific transcript at high levels in skeletal muscle; however, some lines of mice showed low levels of chicken c-ski RNA in other tissues. The TG 8562 line has RNA from the transgene in the heart, although at a lower level than in skeletal muscle. Histopathology of hearts from TG 8562 mice showed that there is no significant effect on this tissue. Line TG 8542 , which does not show any phenotype, had a much lower level of RNA from the transgene in muscle than did the lines that showed the phenotype.

To determine whether the transcript was initiated at the proper site in tissues expressing the ski transgene, we have carried out RNase protection analysis. Uniformly labeled antisense RNA was generated by T7 RNA polymerase from a fragment that spans the MSV LTR and c-ski (see Fig. 4). Ten micrograms of RNA from heart and skeletal muscle from all four lines was hybridized to the labeled antisense RNA and processed as described in Materials and methods. By using RNA from the three positive transgenic lines, a protected fragment of $\sim 980$ bases was seen, which is the expected size if the transcript is initiated at the authentic initiation site within the MSV LTR (Fig. 4). This analysis also gives a more quantitative estimate of the level of transgene RNA in the heart and skeletal muscle of both the phenotypically positive and the phenotypically negative lines of mice. Figure 4 shows that the level of transgene RNA in the heart of TG 8821 is much lower (we estimate perhaps one-tenth to one-twentieth) than the level found in the skeletal muscle. In addition, this analysis shows that the phenotypically negative line TG 8542 has a low, but detectable, level of transgene RNA in skeletal muscle. These data not only suggest that the muscular phenotype is associated with the expression of the chicken c-ski transgene but also that a minimum threshold level of c-ski RNA must be reached to produce the muscular phenotype.

\section{Expression of the c-ski protein}

The underlying assumption is not that the expression of the c-ski RNA gives rise directly to the muscular phenotype but that the phenotype results from the presence of the c-ski protein. We have looked directly for the c-ski protein in Western transfer assays. Although rabbit antisera have been prepared that specifically recognize the $50-\mathrm{kD}$ form of c-ski (Sutrave et al. 1990), these antisera do not work well in Western transfer assays (data not shown). Mouse monoclonal antibodies that recognize c-ski and work well in Western transfer assays have been developed (E. Stavnezer, pers. comm.); however, the use of these reagents presents a technical problem. These monoclonal antibodies were not available in sufficient quantity to permit direct labeling. Indirect labeling pro- 
Sutrave et al.

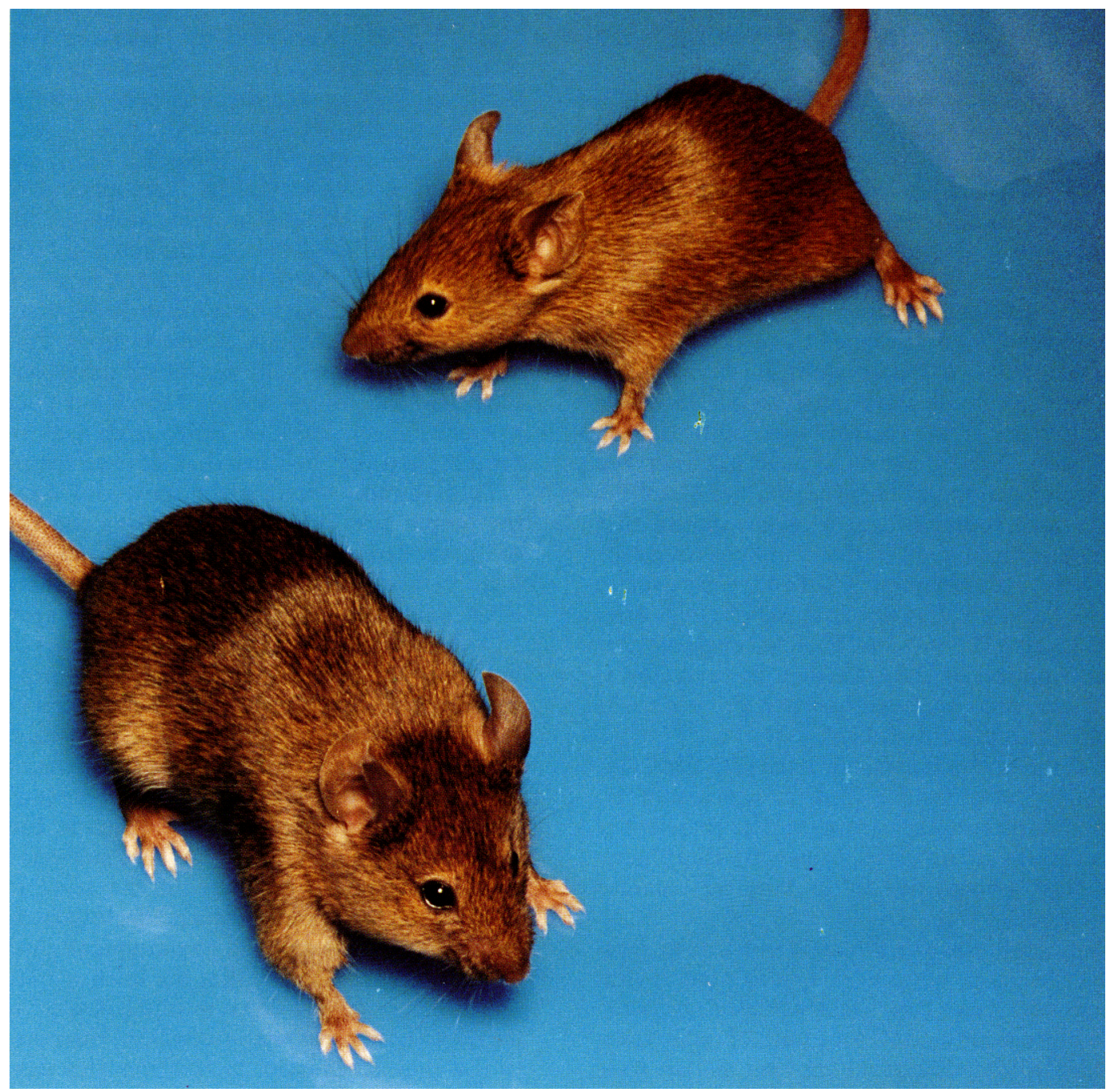

Figure 2. A trangenic mouse that expresses c-ski and normal littermate. The c-ski transgene appears to segregate normally in crosses. The photograph shows a heterozygous mouse that displays the muscular phenotype (foreground) and a DNA-negative littermate. Double-blind DNA analyses confirmed that the muscular phenotype segregates with the transgene.

cedures using, for example, labeled rabbit anti-mouse not only detect the anti-ski monoclonal but also the endogenous mouse heavy chain, which comigrates with the $50-\mathrm{kD}$ form of $\mathrm{c}-\mathrm{ski}$ made from the transgene. To avoid this problem, we prepared extracts of muscle and control tissue (liver) from normal controls and from the transgenic mice. The endogenous mouse antibodies were removed from these extracts by precipitation with rabbit anti-mouse antibody (see Materials and methods). The resulting supernatants, free of mouse antibodies, were used in Western transfer assays. Only affected tissues (skeletal muscle) from the transgenic animals contain the 50-kD c-ski protein (Fig. 5). These data also suggest that there may be differences in the level of the c-ski protein in the muscles of the three positive lines; however, the complexities of the manipulations in this experiment make quantitative interpretation a questionable proposition.
Analysis of the muscle tissue in line TG 8566

It will be necessary to analyze muscle tissue from each of the transgenic lines in detail. We have begun by analyzing skeletal muscles from line TG 8566 . The myocardium was normal, and there were no abnormalities of visceral smooth muscle in these animals (data not shown). Figure 6, A and B, compares cross sections made precisely through the middle of the plantaris muscle from mature male controls and transgenic mice. Crosssectional area of the control is $2.7 \mu \mathrm{m}^{2}$ and that of the TG 8566 mouse is $9.4 \mu \mathrm{m}^{2}$, more than three times the control value. This massive growth is generalized. Comparable increases in cross section were found in almost all axial and appendicular muscles throughout male and female mice of line TG 8566 . Only three muscles were found that appear to be normal: the tongue, the diaphragm, and the soleus; these are the same size in trans- 


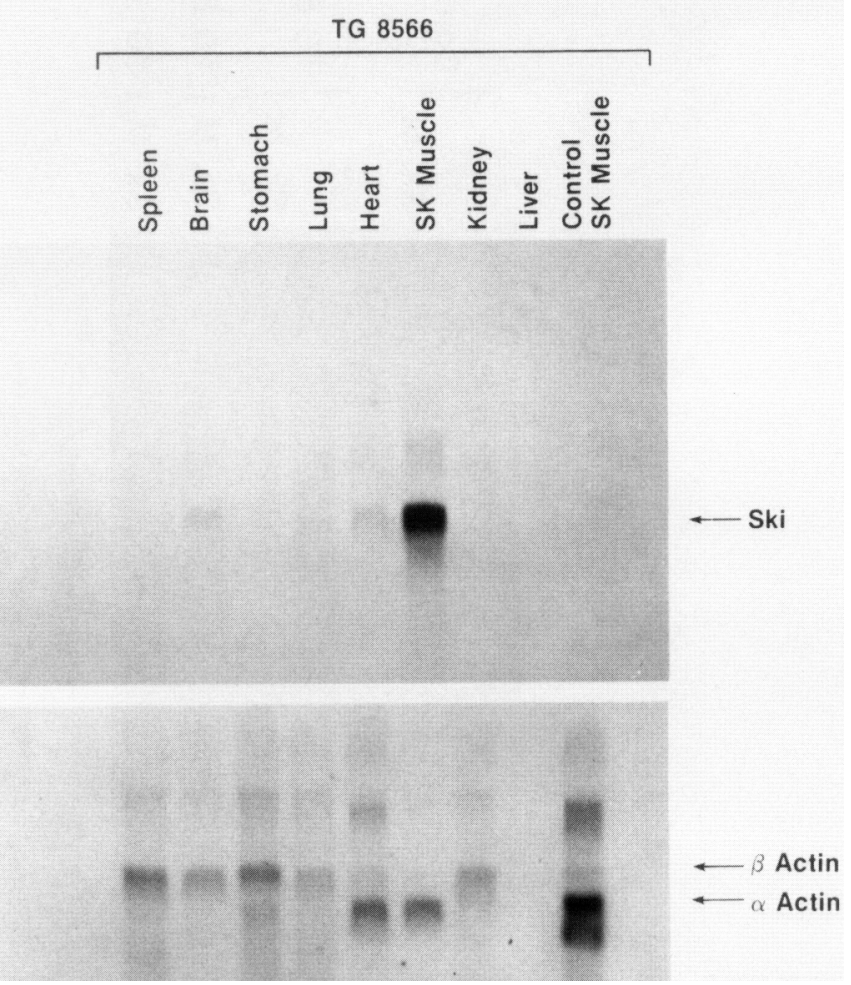

Figure 3. Northern transfer analysis of transgene expression. Twenty micrograms of total RNA from various tissues was fractionated by electrophoresis and transferred to nitrocellulose membranes. The transfers were first probed with chicken c-ski, and the filters were then stripped and reprobed with a chicken $\beta$-actin cDNA (Cleveland et al. 1980). (A) Analysis of RNA isolated from various tissues of a mouse of line TG 8566 . The top autoradiogram is from a filter after hybridization with chicken c-ski. The expected position of migration of the c-ski message appropriately transcribed from the transgene is $2.5 \mathrm{~kb}$. The position corresponding to $2.5 \mathrm{~kb}$ is marked (ski). The bottom autoradiogram is from the same filter following hybridization to a chicken $\beta$-actin cDNA. The $\beta$-actin cDNA will not only hybridize with $\beta$-actin mRNA but also with other actin messages. The expected position of migration of both $\beta$ - and $\alpha$-actin mRNAs are indicated at right. $(B)$ These autoradiograms are similar to those in $A$, except that the RNAs derive from three other transgenic lines. The lines used to prepare the RNAs are indicated at the top. The slightly different appearance of $A$ and $B$ arises because filters shown in $B$ were done at the same time; those in $A$ were done on a different day.

B

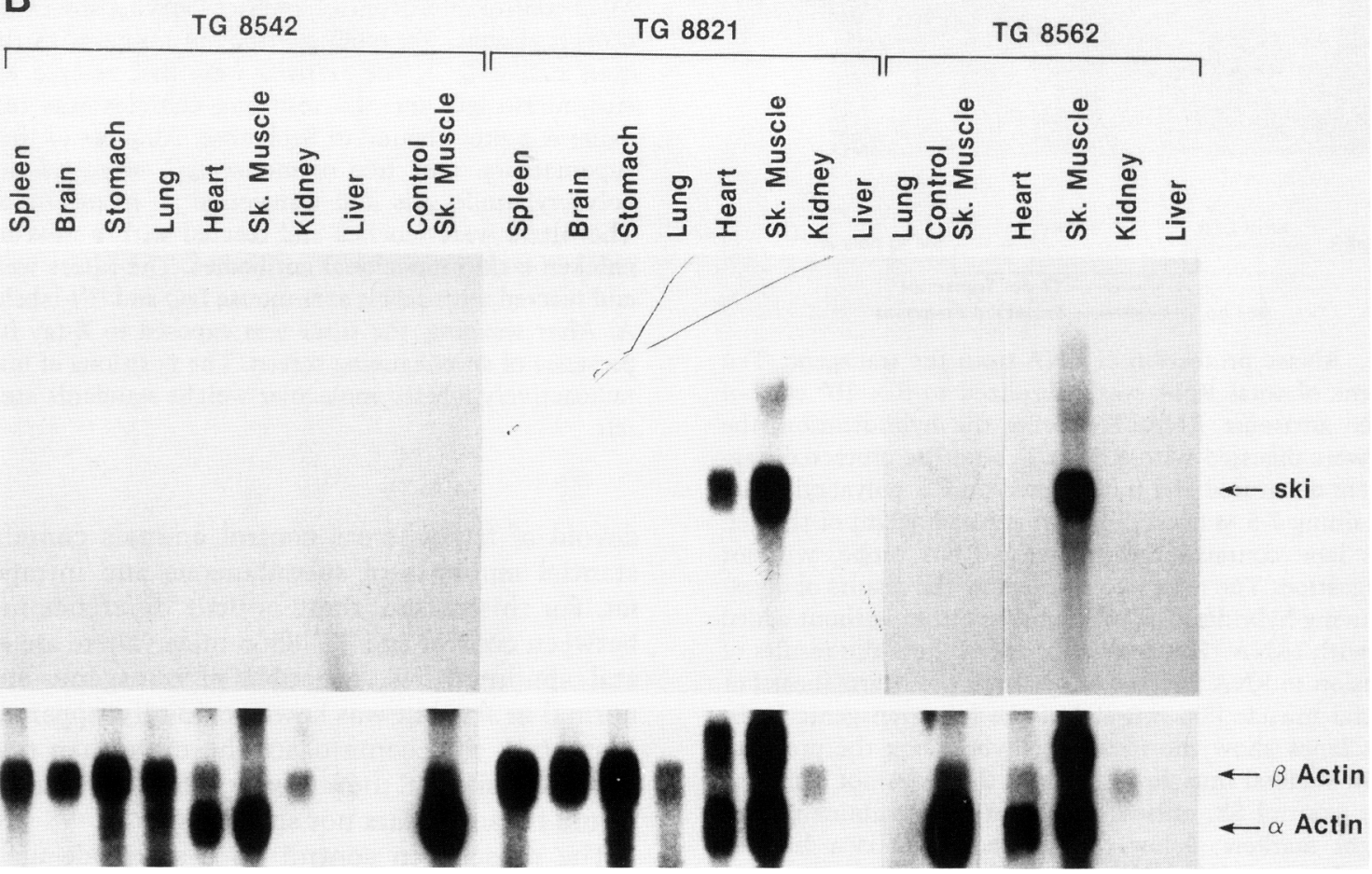

genic as in control muscles (see Fig. 7). RNA was isolated from the diaphragm and soleus muscles of TG 8566 mice. Northern transfer analysis shows that the level of chicken c-ski RNA is much lower in these two phenotypically normal muscles than in the affected muscles from the same line (Fig. 8).

The most obvious additional gross morphologic abnormality is that transgenic animals were almost totally 


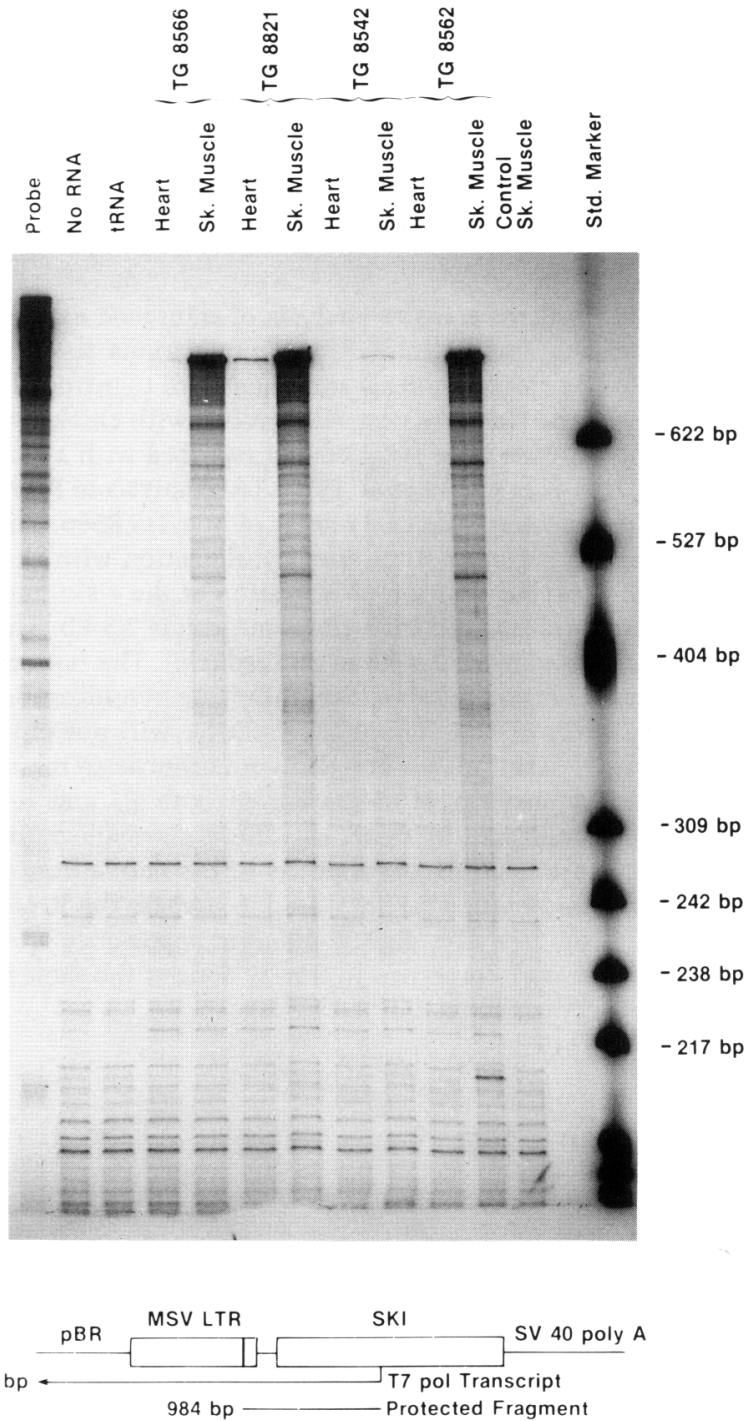

Figure 4. RNase protection of RNA from the transgene. Ten micrograms of total RNA was hybridized to $5 \times 10^{5} \mathrm{cpm}$ of ${ }^{32}$ P-labeled antisense RNA. Following the hybridization, the samples were digested with RNase $T_{1}$, and the protected fragments were denatured and fractionated on $6 \%$ polyacrylamide gels containing $7.5 \mathrm{M}$ urea. (Top) An autoradiogram of the gel. The first lane contains the antisense RNA probe, without RNase digestion. The next two lanes show the results of digestion following hybridization of the probe either without added RNA or with tRNA. The next eight lanes show the results of hybridization to RNA isolated either from the hearts (heart) or the skeletal muscle (Sk. muscle) of the four transgenic lines. The next lanes show the results of hybridizing the probe to RNA from skeletal muscle of a mouse that does not carry the transgene (control Sk. muscle). The last lane contains molecular weight markers. Below the autoradiogram is a diagram showing a drawing of the MSV LTR c-ski expression cassette in relation to the antisense RNA probe. The T7 transcript begins in the middle of the c-ski-coding region and goes entirely through the MSV LTR into adjacent sequences that derive from pBR322 (marked pBR). If the transcripts deriving from the transgene initiate appropriately, then a fragment of 984 bases should be protected.

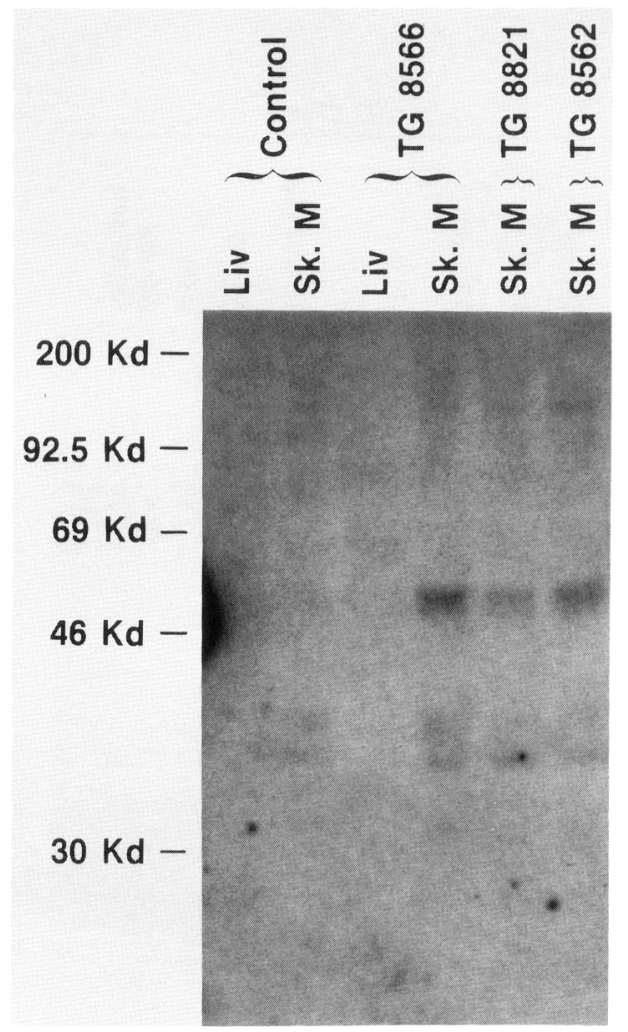

Figure 5. Chicken c-ski protein expression in transgenic mice. Extracts were made from the liver (Liv) or skeletal muscle (Sk. $\mathrm{M}$ ) of control mice (control) or mice carrying and expressing the c-ski transgene. To avoid spurious reactions with the endogenous mouse IgGs, the extracts were first reacted with rabbit anti-mouse IgG and the resulting complex was removed by using A protein bound to Sepharose. Aliquots of the resulting supernatants, now free of mouse IgG, were fractionated on polyacrylamide gels and transferred to nitrocellulose filters. The filters were blocked and reacted with a mixture of antichicken c-ski monoclonal antibodies. The filters were washed and reacted with rabbit anti-mouse IgG and ${ }^{125}$ I-labeled protein A. After washing, the filter was exposed to X-ray film in the presence of an enhancing screen. The positions of migration of radioactively labeled molecular weight standards are shown at left.

devoid of fat, whereas control animals contained substantial amounts of subcutaneous and intraperitoneal fat. For this reason, there is little difference in weights between control and TG 8566 mice. There are also skeletal abnormalities; the tibia of transgenic animals is normal in size but was bowed cranially, apparently as an adaptation to accommodate the more than twofold increase in size of the anterior tibia and extensor digitorum muscles (data not shown).

The muscles in control mice are made up of fibers with a range of cross-sectional areas. The range of sizes is greatly extended in TG 8566 mice (Figs. 6 and 7). Not all fibers are affected; the hypertrophy is limited to a select population of fibers (Fig. 6D). There are also several fibers that are smaller in size than any of the fibers seen in the controls (Fig. 7). Whether this is a direct effect of 


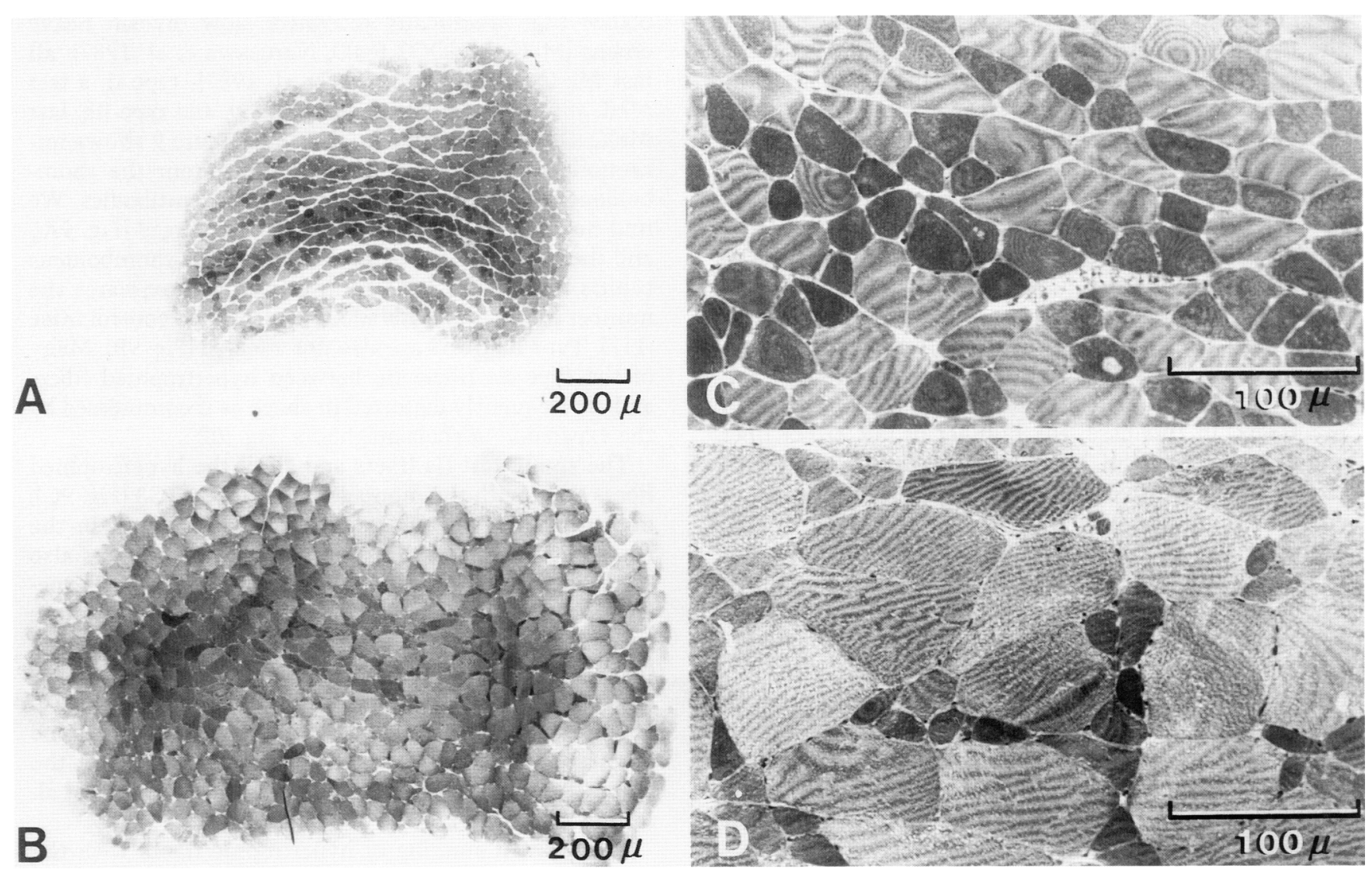

Figure 6. Cross sections made precisely through the middle of the plantaris muscle from control mouse $(A)$ and from a mouse of line TG $8566(B)$. Both illustrations are at the same magnification; the size marker is $200 \mu \mathrm{m}$. $(C)$ Higher power illustration from the plantaris of control; $(D)$ higher power illustration from the plantaris of an affected mouse. Size markers in $(C)$ and $(D)$ are $100 \mu \mathrm{m}$.
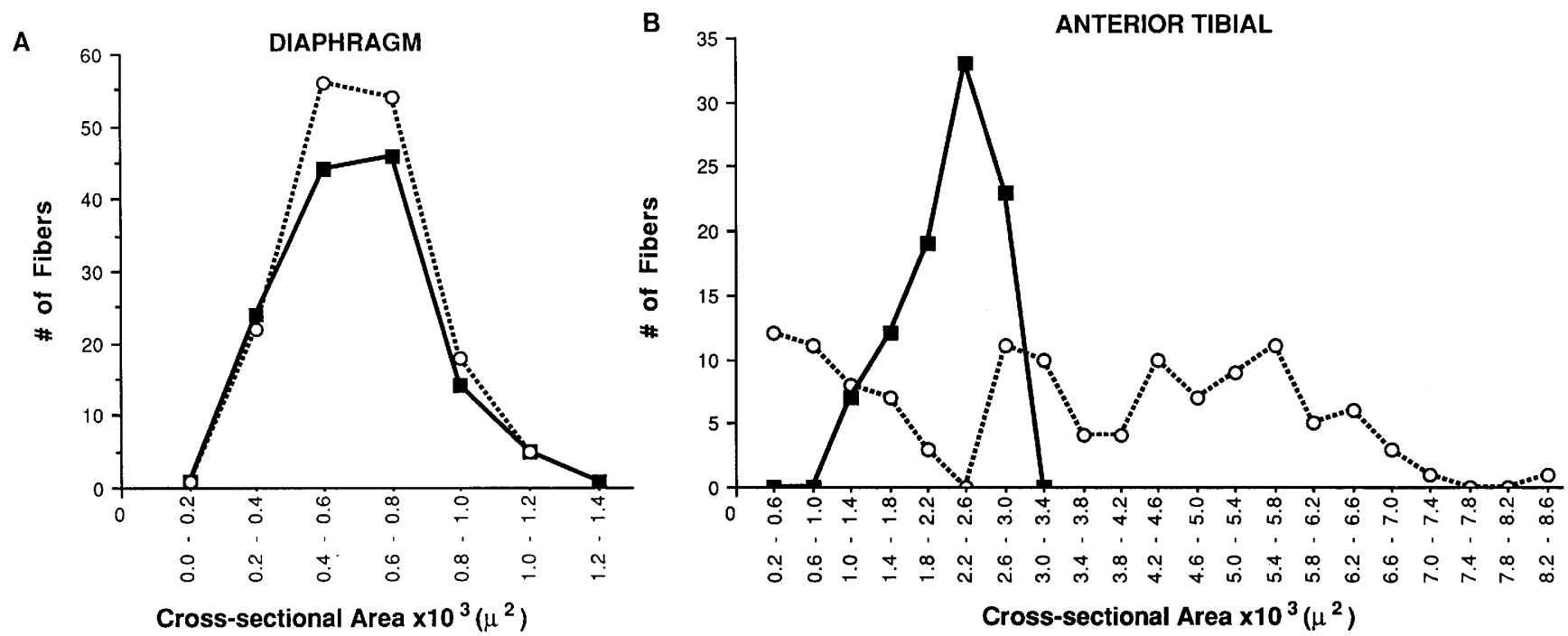

Figure 7. Distribution of fiber diameters in selected muscles from normal and transgenic mice. The diaphragm appears normal in

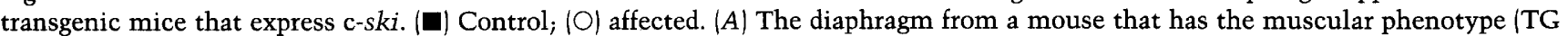
8566) and a diaphragm from a normal control mouse were sectioned; the number of individual muscle fibers of a given cross-sectional area were tallied. $(B)$ The anterior tibial muscle is grossly enlarged in mice from the line TG 8566 . Transverse sections were prepared from both a transgenic mouse and a control mouse. The number of fibers of each given cross-sectional area were tallied. This muscle is composed of two distinct types of fibers, some smaller and others larger, than the fibers found in the controls (see also Fig. 6). 
c-ski expression or simply a mechanical effect caused by the hypertrophy of the adjacent fibers is not yet clear. Hypertrophy of these fibers apparently accounts for the increase in muscle mass in line TG 8566 . We have found no evidence that the number of fibers is significantly increased in individual muscles. For example, the population of fibers in the control plantaris is $912 \pm 111$ $(n=3)$ and in TG 8566 is $991 \pm 87(n=3)$. Similarly, we found no difference in the total number of fibers in the extensor digitorum longus muscle of TG 8566 and control mice (data not shown).

Because ski can act as a mitogen, hypertrophy could be the result of myoblast (satellite cell) hyperplasia, followed by fusion with a previously defined population of myofibers. In this case, the number of nuclei per fiber would be increased in TG 8566 muscles compared with controls. We counted the number of nuclear profiles in cross sections of fibers from the plantaris, gastrocnemius, and digastricus muscles of TG 8566 mice and control mice $(\sim 500$ for each muscle). For TG 8566 and control plantaris and digastricus, there were, respectively, 0.69 and 0.68 nuclear profiles per fiber. For the gastrocnemius TG 8566 and control, there were 1.20 and 1.02 , respectively. There were no recognizable differences in nuclear morphology in fibers of TG 8566 and control animals. The incidence of nuclear profiles per fiber is not significantly different between the groups. This implies that hypertrophy is not due to the fusion of additional myoblasts. In view of the threefold increase in muscle cross dimension, the nuclear/cytoplasmic ratio is significantly increased in TG 8566 mice.

To investigate which types of fibers are affected in the line TG 8566, we have used three monoclonal anti-

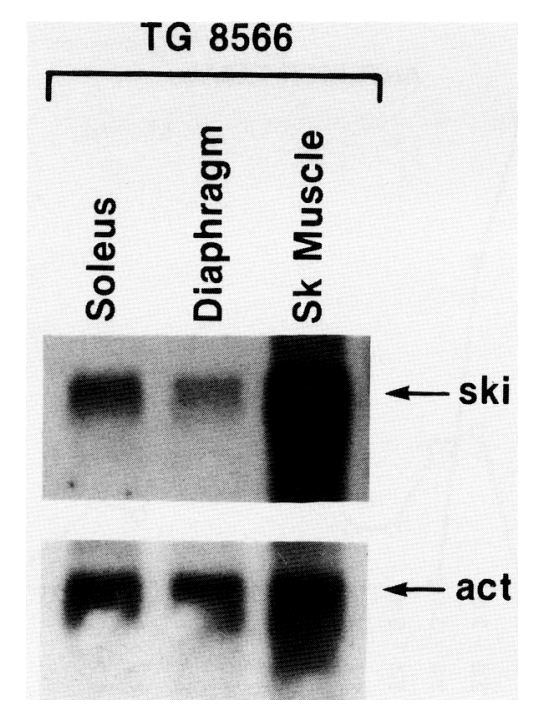

Figure 8. Transgene expression in specific muscles from TG 8566. Twenty micrograms of total RNA was fractionated by electrophoresis and transferred to nitrocellulose membranes. The transfers were first probed with chicken c-ski, and the filters were stripped and reprobed with chicken $\beta$-actin cDNA (Cleveland et al. 1980). The RNA was isolated from the diaphragm or the soleus, or from bulk skeletal muscle (Sk muscle). bodies that specifically recognize slow myosin heavy chains (MHCs) (NOQ7 5 4D, Narusawa et al. 1987); all fast MHCs (2G3, Narusawa et al. 1987); type II, a fast MHC (SC 7 11, Schiaffino et al. 1989), and type IIb, fast MHC (BF-F3, Schiaffino et al. 1989). Figure 9 shows immunofluorescent staining of sections from the rhomboideus capitis muscle with these three antibodies. We find no evidence that slow fibers are enlarged (Fig. 9A), and the total number of slow fibers in the rhomboideus capitis from a TG 8566 mouse (120) approximates the number found in rhomboideus capitis from control mice (117). Type IIa fibers are also not affected (Fig. 9B). Many of the type IIa fibers lie between hypertrophied fibers and are frequently distorted in shape as if compressed by the expansion of their neighbors (Fig. 9B).

The small, fast IIa fibers and all of the hypertrophied fibers stain with the monoclonal antibody $2 \mathrm{G} 3$ (Fig. 9C), indicating that all hypertrophied fibers are fast. In the rhomboideus capitis, most, but not all, large fibers also stain with the monoclonal antibody BF-F3 that is specific for IIb MHC (Fig. 9D). In the plantaris, there is more variation in reactivity, and only $50 \%$ of hypertrophied fibers stain with BF-F3 (data not shown). These results show that the hypertrophic modification of fibers in TG 8566 mice involves at least two types of fast fibers. One of these is type IIb. By exclusion, we suggest that the others are IIx fibers (Schiaffino et al. 1989; Termin et al. 1989; Gorza 1990).

Variation in staining of hypertrophic fibers with the actomyosin ATPase histochemical reaction after acid preincubation, NADH staining for mitochondrial enzyme activity, and periodic acid Schiff (PAS) staining all support the conclusion that more than one fast fiber type is affected in this line of transgenic mice. These results also support the interpretation that both IIb and IIx fibers are hypertrophied.

Occasional necrotic and regenerating fibers were found in some, but not all, muscles of line TG 8566 mice. In the hind limb, these appeared to be most prevalent in the anterior tibial muscle; they were never found in the rhomboideus capitis, a superficial muscle of the neck.

\section{Discussion}

It has already been shown that c-ski and v-ski can affect muscle differentiation in vitro /Colmenares and Stavnezer 1989; P. Sutrave and E. Stavnezer, unpubl.). The three lines of transgenic mice that we have created now show that at least the truncated form of c-ski can affect muscle development in vivo. Although the three lines of mice carry an oncogene, none of the lines appears to have an increased incidence of tumors. We have maintained all of the lines for more than 1 year, and none of the mice have presented with macroscopic tumors in that time; nor have any of the mice examined histologically shown any incidence of microscopic tumors. This result is not totally unexpected, because the v-ski virus is not tumorigenic in chickens unless the birds are injected with infected cells (E. Stavnezer 1988). Moreover, the three strains of mice do not express high levels of the 

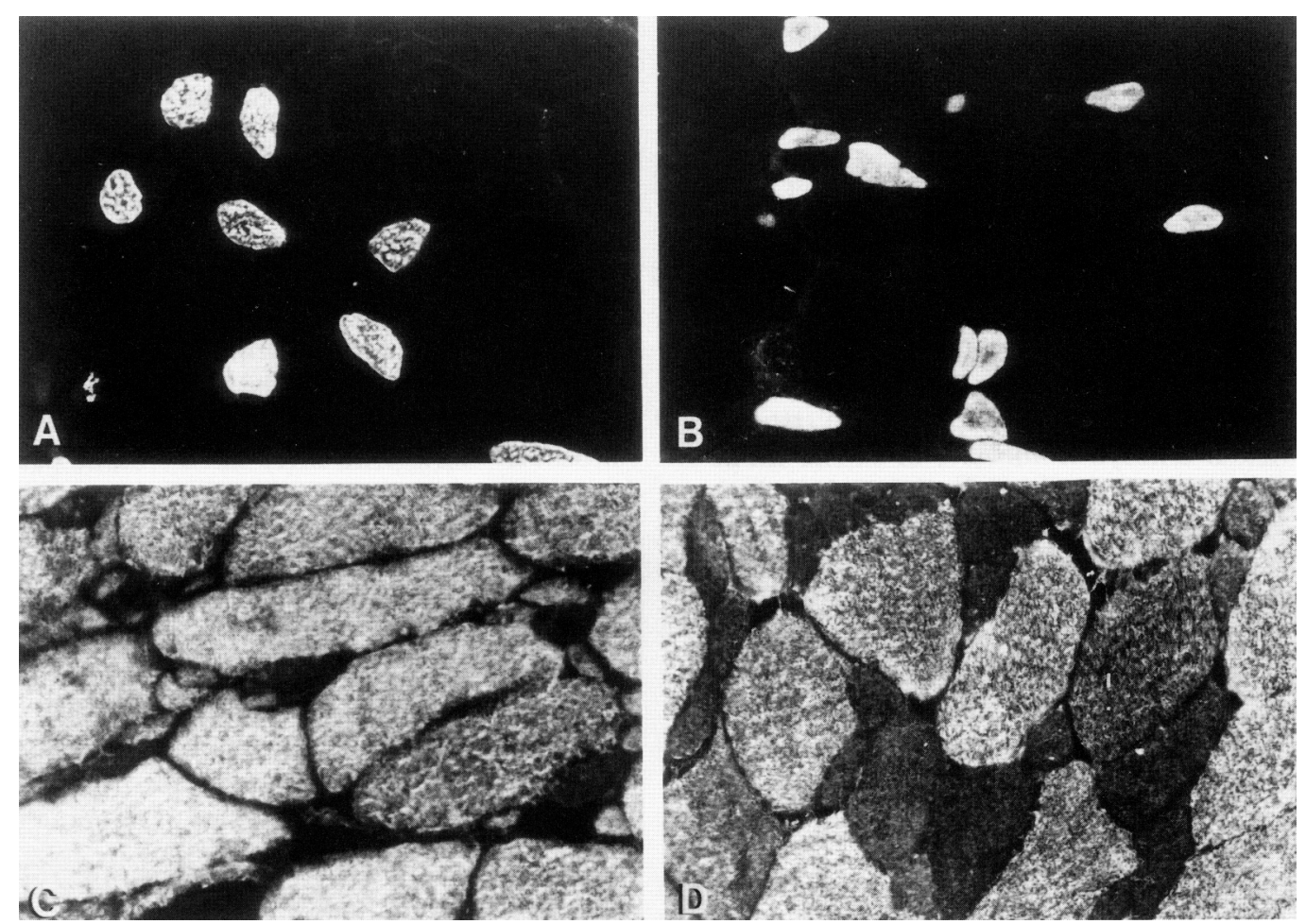

Figure 9. Immunofluorescence staining of sections made through the middle of the rhomboideus capitis muscle of an affected mouse. $(A)$ Staining with monoclonal antibody NOQ7 $54 \mathrm{D}$, specific for slow MHC. Slow fibers are not hypertrophied. $(B)$ Staining with monoclonal antibody SC 711 specific for IIa MHC. IIa fibers are not hypertrophied. $(C)$ Staining with monoclonal antibody 2G3, which reacts with all fast $\mathrm{MHC}$ isoforms. All hypertrophied fibers stain with this antibody. $(D)$ staining with $\mathrm{m} / \mathrm{a}$ BF-F3 specific for IIb MHC. Many, but not all, hypertrophied fibers stain. Magnification, $230 \times$.

transgene except in skeletal muscle. This is consistent with the interpretation that c-ski affects skeletal muscle cells directly and not as a secondary consequence of altered motor neuron function. There is no detectable expression of c-ski in the CNS, and electromyogram analysis of transgenic animals did not reveal alterations in electrical activity compared to control animals (data not shown).

The observation that expression was restricted to muscle was unexpected because the MSV LTR has been shown to express in a variety of tissues when linked to other genes (Khillan et al. 1987; D. Cleveland, pers. comm.). Two obvious possibilities exist: (1) The c-ski cDNA plays some role in directing the muscle-specific expression or in the accumulation of the RNA; and (2) mice that would have expressed the transgene in other tissues did not survive. The c-ski portion of the transgene derives from a chicken c-ski cDNA from which all of the $5^{\prime}$ untranslated region, all of the $3^{\prime}$-untranslated region, and a portion of the coding region were removed. If there are regulatory elements (or elements that specifically stabilize this RNA in muscle), these elements must reside within the coding region. We do not favor this interpretation because normal chicken c-ski mRNAs do not accumulate in muscle (data not shown), and c-ski RNAs expressed from a retroviral vector are stable in cultured fibroblasts (Sutrave et al. 1990).
The alternate interpretation is that the expression of the transgene in other tissues is incompatible with survival. Although this is a somewhat more attractive proposal, a large number of founder mice carried the transgene (a total of 44), and it did not appear to be difficult to obtain transgenics. We do not know the expression status of the transgene in the founders not bred for making transgenic lines. Additional experiments, now under way, with c-ski cDNAs linked to other promoters may help resolve these issues.

The data also suggest that a threshold level of the c-ski protein is necessary to obtain the muscular phenotype. The one phenotypically negative line we have maintained, TG 8542, expresses what appears by RNase protection to be the appropriate RNA in skeletal muscle, although at a level perhaps $2-4 \%$ of that seen in the three phenotypically positive lines. In addition, one line expresses the transgene in the heart but does not show any discernible cardiac abnormalities. Again, the level of RNA expression is, at most, $5-10 \%$ of that seen in the muscles of the three phenotypically positive lines. These data suggest that the minimal threshold level to see an effect of the transgene is high, probably several thousandfold the levels of endogenous c-ski expression in the chicken tissues that we have examined (Sutrave and Hughes 1989). Unfortunately, it has not yet been possible to accurately measure the levels of expression 
of the endogenous c-ski protein or to accurately measure the levels of the protein produced by the transgene except in muscle where the protein is present at relatively high levels.

Based on a comparison of the three phenotypically positive and the one phenotypically negative mouse lines, it would appear that high levels of the truncated c-ski protein are required to obtain the muscular phenotype. We do not believe that this requirement results from the truncation of the c-ski cDNA because the truncated form of the c-ski cDNA is as effective as the fulllength forms in inducing either morphological transformation of chicken embryo fibroblasts or in the induction of muscle in cells derived from quail embryo body wall.

We have only attempted to examine the musculature of one of the transgenic lines in any detail. The decision to begin with line TG 8566 was arbitrary. Not only is expression of the transgene and its effect restricted to muscle, the expression and the effects appear, at least in the line TG 8566 , to be confined to certain muscles. Although it is clear that the increase in muscle results from an increase in the size of individual fibers, we do not yet know how the fiber size is increased. The same number of nuclei are seen in cross sections of the same muscles from line TG 8566 and normal controls. The results suggest that the hypertrophied fibers derive from approximately the same number of myoblasts as do their normal counterparts. These data also suggest that the changes in the muscles of TG 8566 mice are not the result of the mitogenic effects, but of the myogenic effects, of ski.

The effects of c-ski expression are restricted to certain fiber types, which suggests the possibility that c-ski expression is also limited to the affected fibers. This possibility is under investigation; however, the affected fibers are not all of the same type. Histochemical analysis of actomyosin ATPase activity and immunochemical results with a monoclonal antibody specific for IIb MHC show that approximately half the hypertrophied fibers in the plantaris are of the IIb type. The other $50 \%$ fail to stain with BF-F3, a monoclonal antibody specific for IIb MHC. Because all of the hypertrophied fibers stain with monoclonal antibody 2G-3, which recognizes all fast MHCs, we tentatively interpret the other hypertrophied fibers as IIx in phenotype. This is consistent with the criteria outlined by Gorza (1990) and the observation that hypertrophied fibers with intermediate ATPase staining after preincubation at $\mathrm{pH} 4.65$ also have intermediate mitochondrial enzyme activities.

Although the primary effects of the ski transgene appear to be on IIb and probably IIx fibers, the induced hypertrophy may be coupled with systemic metabolic changes, for fat is virtually nonexistent in TG 8566 mice. Either the fat cells themselves are affected or the metabolic energy of the animal is directed toward increased contractile protein synthesis. Because the affected IIb fibers are glycolytic in metabolism, gluconeogenesis is presumably very active in the liver to sustain muscle function.
According to morphological criteria, three muscles, the tongue, the soleus, and the diaphragm, appear to be unaffected in line TG 8566. The level of transgene RNA is substantially lower in both the diaphragm and the soleus than in affected leg muscle. There is a large population of IIx fibers in the diaphragm of the mouse (D. Parry, pers. comm.). This result underscores the complexity of the control of expression of the ski transgene. The RNA data suggest (but do not prove) that the specificity of the ski effect is principally due to the specificity with which $s k i$ is expressed.

It will be useful to know whether all three lines of muscular transgenic mice have similar patterns of ski expression and response in the various fibers of individual muscle. If the pattern is closely conserved, it would suggest that ski, itself, and not selection, must play at least some role in determining which specific fibers are affected.

Whether or not the muscular mice will provide clues useful for the elucidation of the normal functions of c-ski, they do provide a means to assess some of the properties of c-ski and they should also provide a system to analyze growth regulation in developing muscle.

\section{Materials and methods \\ Transgene and generation of the transgenic mice}

The transgene is shown schematically in Figure 1. The construction of the ski portion of the transgene has been described (Sutrave and Hughes 1989; Sutrave et al. 1990). Briefly, a truncated chicken c-ski cDNA called $\triangle \mathrm{FB} 29$ had been previously cloned into the adaptor plasmid Cla12Nco. The $\triangle$ FB29 segment was released from the adaptor plasmid by ClaI digestion, and the $5^{\prime}$ overhangs were filled in using the Klenow fragment of Escherichia coli DNA polymerase I and all four dNTPs. This blunt-ended fragment was ligated to the pMEX neo vector (B. Stanton and D. Martin-Zanca, pers. comm.), which had been digested with EcoRI restriction enzyme and blunt-ended with the Klenow fragment. Clones were selected that had inserts in the correct orientation and were digested with both $P_{V u I}$ and $N r u I$ restriction endonucleases. These enzymes release a segment that contains the $\triangle$ FB29 cDNA flanked by an MSV LTR and the SV40 poly(A) signal (see Fig. 1). This fragment was gelpurified and used to inject fertilized mouse eggs (Hogan et al. 1986).

\section{DNA/RNA analysis}

Total cellular DNA and RNA were isolated by standard procedures. For RNA isolation, tissues were frozen in liquid nitrogen immediately following dissection, homogenized in RNAzol (Cinna Biotex), and processed according to the manufacturer's recommendation. For Northern transfer analysis, approximately $20 \mu \mathrm{g}$ of total RNA from different tissues was fractioned by electrophoresis on $1.5 \%$ agarose gels containing $2.2 \mathrm{M}$ formaldehyde. The RNA was transferred to nitrocellulose membranes and probed either with a nick-translated chicken ski cDNA or a chicken $\beta$-actin cDNA. The coding region of the $\beta$-actin cDNA cross-reacts with the messages for the other actins and can be used to validate the quantity and quality of RNA from most tissues.

RNase protection assays were carried out as described by Melton (Melton et al. 1984). A 1.8-kb PvuI-BgII fragment was 
subcloned in the Bluescript $\mathrm{KS}$ vector and used to generate radioactively labeled RNA from the T7 promoter. Approximately $10 \mu \mathrm{g}$ of total RNA was hybridized with $5 \times 10^{5} \mathrm{cpm}$ of probe. The hybridizations were carried out overnight at $50^{\circ} \mathrm{C}$ in $80 \%$ formamide and $1 \times$ buffer $(5 \times$ hybridization buffer is $0.2 \mathrm{M}$ PIPES at $\mathrm{pH}$ 6.4, $2 \mathrm{~m}$ sodium chloride, $5 \mathrm{~mm}$ EDTA). After hybridization, the samples were diluted in ribonuclease digestion buffer (10 mM Tris- $\mathrm{Cl}$ at $\mathrm{pH} 7.5,0.3 \mathrm{M}$ sodium chloride, $5 \mathrm{~mm}$ EDTA) and treated with RNase $\mathrm{T} 1$ at a concentration of $1 \mathrm{U} / \mu \mathrm{l}$ for $60 \mathrm{~min}$ at $30^{\circ} \mathrm{C}$. The RNase digestions were stopped by adding $10 \mu \mathrm{l}$ of $20 \%$ SDS and $4 \mu \mathrm{l}$ of proteinase $\mathrm{K}$ (stock 10 $\mathrm{mg} / \mathrm{ml}$ ) and incubating at $37^{\circ} \mathrm{C}$ for $15 \mathrm{~min}$. The digested samples were extracted with phenol chloroform $(1: 1$ mixture $)$ and ethanol-precipitated with carrier tRNA. The pellet was rinsed once with $70 \%$ ethanol, dried, and dissolved in formamide containing bromophenol blue and xylene cyanol dyes. The samples were denatured at $100^{\circ} \mathrm{C}$ and separated on $6 \%$ polyacrylamide gels containing $7.5 \mathrm{M}$ urea.

\section{Protein analysis}

For detection of ski protein in tissues from the transgenic and control mice, 1-5 $\mathrm{mg}$ of tissue was homogenized in $1 \mathrm{ml}$ of RIPA buffer, $20 \mathrm{~mm}$ Tris- $\mathrm{Cl}$ (pH 7.5), $150 \mathrm{mM} \mathrm{NaCl}, 0.5 \%$ SDS, $0.5 \%$ NP- $40,0.5 \%$ sodium deoxycholate, $1 \mathrm{~mm}$ EDTA, $1 \mathrm{~mm}$ PMSF, and $35 \mathrm{U} / \mathrm{ml}$ of aproteinin. The homogenate was clarified by centrifugation at $10,000 \mathrm{rpm}$ for $10 \mathrm{~min}$. Mouse IgG was removed from $100 \mu$ lof the supernatant by incubation with 10 $\mu \mathrm{l}$ of $1 \mathrm{mg} / \mathrm{ml}$ rabbit anti-mouse IgG (in PBS) for $2 \mathrm{hr}$ on ice. The complex was removed by adding $100 \mu \mathrm{l}$ of $40 \%$ protein A-Sepharose beads in RIPA buffer. The resulting supernatant was collected, and $20 \mu \mathrm{l}$ was fractionated on $10 \%$ SDS-polyacrylamide gels. The proteins were transferred to nitrocellulose membranes overnight in buffer containing $0.125 \mathrm{M}$ Tris-Cl, $0.092 \mathrm{M}$ glycine, and $20 \%$ methanol $(\mathrm{pH} 8.3)$. The filters were blocked with $4 \%$ dry nonfat milk in TBS buffer $10.5 \mathrm{M}$ Tris-Cl at $\mathrm{pH} 7.4$ and $0.2 \mathrm{M}$ sodium chloride) for $2 \mathrm{hr}$ at room temperature and incubated with a mixture of three anti-ski monoclonal antibodies at a dilution of $1: 3000$ for $2 \mathrm{hr}$ at room temperature; they were then washed three times with TBS. Secondary incubations with rabbit anti-mouse IgG were done for $2 \mathrm{hr}$ at room temperature ( $1: 2000$ dilution from a $1 \mathrm{mg} / \mathrm{ml}$ stock). The filter was washed as described above and finally incubated with 5 $\mu \mathrm{Ci}$ of ${ }^{125} \mathrm{I}$-labeled protein A (Amersham, sp. act. $30 \mathrm{mCi} / \mathrm{mg}$ ) for $2 \mathrm{hr}$ at room temperature. The filter was washed three times with TBS and exposed to XAR Kodak film at $-70^{\circ} \mathrm{C}$ for 6 days.

\section{Histology}

For histology, selected muscles were isolated so that they remained attached at their origin and insertion; they were then fixed in $2 \%$ formaldehyde, $2 \%$ gluteraldehyde. Fixed muscle was transected precisely through the middle of the muscle belly and embedded in JB4 plastic (Polysciences, Warrenton, PA).

For immunocytochemistry, tissues were snap-frozen in isopentane that was cooled in liquid nitrogen. The procedure for immunochemical staining was as outlined in Narusawa et al. (1987).

\section{Acknowledgments}

We thank Dr. R.B. Fitzsimons for the generous gift of monoclonal antibody NOQ7 5 4D and Dr. S. Schiaffino for the generous gift of monoclonal antibodies SC 711 and BF-F3. The skilled technical assistance of John Leferovich is gratefully acknowledged. We thank Dr. Nancy Jenkins, Dr. Neal Copeland,
Debbie Swing, and Bryn Eagelson for generating and maintaining the transgenic mice. We are grateful to Dr. Robert Kovatch and Shirley Hale for histopathological analysis of tissues. We also thank Dr. B. Stanton and Dr. D. Martin-Zanca for their gift of the expression plasmid pMEX, and Dr. E. Stavnezer for providing monoclonal antibodies and helpful discussions. P.S. thanks all of his associates for constant suggestions, help, encouragement, and critical comments during the project. We also thank $\mathrm{H}$. Marusiodis for expert secretarial assistance. Research was sponsored, in part, by the National Cancer Institute, Department of Health and Human Services (DHHS), under contract NO1-CO-74101 with ABL. The contents of this publication do not necessarily reflect the views or policies of the DHHS, nor does mention of trade names, commercial products, or organizations imply endorsement by the U.S. government.

The publication costs of this article were defrayed in part by payment of page charges. This article must therefore be hereby marked "advertisement" in accordance with 18 USC section 1734 solely to indicate this fact.

\section{References}

Barkas, A.E., D. Brodeur, and E. Stavnezer. 1986. Polyproteins containing a domain encoded by the $\mathrm{v}$-ski oncogene are located in the nuclei of SKV transformed cells. Virology 151: $131-138$.

Cleveland, D.W., M.A. Lopata, R.J. MacDonald, N.J. Cowan, W.J. Rutter, and M.W. Kirschner. 1980. Number and evolutionary conservation of alpha- and beta-tubulin and cytoplasmic beta- and gamma-acting genes using specific cloned cDNA probes. Cell 20: 95-105.

Colmenares, C. and E. Stavnezer. 1989. The ski oncogene induces muscle differentiation in quail embryo cells. Cell 59: 293-303.

Gorza, L. 1990. Identification of a novel type 2 fiber population in mammalian skeletal muscle by combined use of histochemical myosin ATPase and anti myosin monoclonal antibodies. I. Histochem. Cytochem. 38: 257-265.

Hogan, B., F. Constantini, and E. Lacy. 1986. Manipulating the mouse embryo: A laboratory manual. Cold Spring Harbor Laboratory, Cold Spring Harbor, New York.

Hughes, S.H., I.J. Greenhouse, C.J. Petropoulos, and P. Sutrave. 1987. Adaptor plasmids simplify the insertion of foreign DNA into helper independent retroviral vectors. I. Virol. 61: 3004-3012.

Khillan, J.S., M.K. Oskarsson, F. Propst, T. Kuwabara, G.F. Vande Woude, and H. Westphal. 1987. Defects in lens fiber differentiation are linked to c-mos overexpression in transgenic mice. Genes Dev. 1: 1327-1335.

Li, Y., C.M. Turck, J.J. Teumer, and E. Stavnezer. 1986. Unique sequence, ski, in Sloan-Kettering avian retrovirus with properties of a new cell derived oncogene. J. Virol. 57: 10651072.

Melton, D.A., P.A. Krieg, M.R. Rebagliati, T.M. Maniatis, and M.R. Green. 1984. Efficient in vitro synthesis of biologically active RNA and RNA hybridization probes from plasmids containing a bacteriophage SP6 promoter. Nucleic Acids Res. 12: 7035-7036.

Nagase, T., G. Mizuguchi, N. Nomura, R. Ishizaki, Y. Ueno, and S. Ishii. 1990. Requirement of protein co-factor for the DNA-binding function of the human ski proto-oncogene product. Nucleic Acids Res. 18: 337-343.

Narusawa, M., R.B. Fitzsimons, S. Izumo, B. Nadal-Ginard, N.A. Rubinstein, and A.M. Kelly. 1987. Slow myosin in developing rat skeletal muscle. J. Cell Biol. 104: 447-459.

Schiaffino, S., L. Gorza, S. Sartore, L. Saggin, S. Ausoni, M. 
Sutrave et al.

Vianello, K. Gundersen, and T. Lomo. 1989. Three myosin heavy chain isoforms in type II skeletal muscle fibers. $I$. Muscle Res. Cell Motil. 10: 197-205.

Stavnezer, E. 1988. The ski gene. In The oncogene handbook (ed. E.P. Reddy, A. Skalka, and T. Curran), pp. 393-401. Elsevier Science Publishing Co., Amsterdam.

Stavnezer, E., D.S. Gerhard, R.C. Binari, and I. Balzas. 1981. Generation of transforming viruses in culture of chicken fibroblasts infected with avian leukosis virus. J. Virol. 39: $920-934$

Stavnezer, E., A.E. Barkas, L.A. Brennan, D. Brodeur, and Y. Li. 1986. Transforming Sloan-Kettering viruses generated from the cloned v-ski oncogene by in vitro and in vivo recombination. J. Virol. 57: 1073-1083.

Sutrave, P. and S.H. Hughes. 1989. Isolation and characterization of three distinct cDNAs for the chicken c-ski gene. Mol. Cell. Biol. 9: 4046-4051.

Sutrave, P., T.D. Copeland, S.D. Showalter, and S.H. Hughes. 1990. Characterization of chicken c-ski oncogene products expressed by retroviral vectors. Mol. Cell. Biol. 10: 31373144.

Termin, A., R.S. Staron, and D. Pette. 1989. Myosin heavy chain isoforms in histochemically defined fiber types of rat muscle. Histochemistry 92: 453-457. 


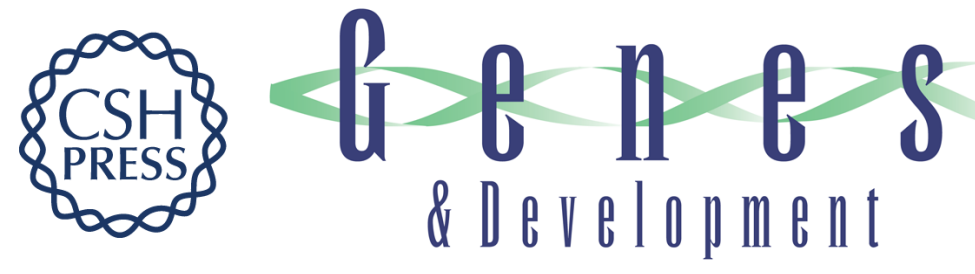

\section{ski can cause selective growth of skeletal muscle in transgenic mice.}

P Sutrave, A M Kelly and S H Hughes

Genes Dev. 1990, 4:

Access the most recent version at doi:10.1101/gad.4.9.1462

References This article cites 16 articles, 8 of which can be accessed free at:

http://genesdev.cshlp.org/content/4/9/1462.full.html\#ref-list-1

License

Email Alerting Receive free email alerts when new articles cite this article - sign up in the box at the top Service right corner of the article or click here.

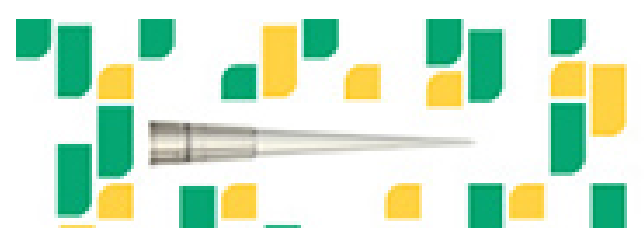

Focused on your science.

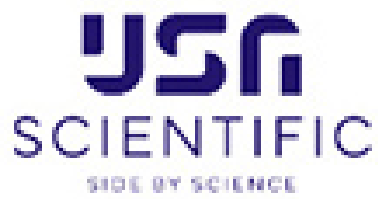

Copyright @ Cold Spring Harbor Laboratory Press 